\title{
COMUNICAÇÃo
}

\section{REAPARECIMENTO DA POSITIVIDADE DE XENODIAGNÓSTICO 15 ANOS APÓS TRATAMENTO ESPECÍFICO DA DOENÇA DE CHAGAS}

\author{
Guido Carlos Levi, Esper Georges Kallás, João Silva de Mendonça e Vicente Amato Neto
}

A relação entre parasitemía e história natural da doença de Chagas ainda não está cabalmente definida. A observação do comportamento da parasitemia em paralelo ao tratamento específico e à evolução da enfermidade é ponto fundamental para o entendimento da fisiopatogenia da instalação das formas cardíaca e digestiva, exponenciais sob o ponto de vista clínico ${ }^{12}$. Nesse contexto, inclusive, aguarda esclarecimento o significado da negativação do xenodiagnóstico após terapêutica antiTrypanosoma cruzi, e discute-se se ocorre realmente cura, do ponto de vista de atividade parasitária, supressão temporária ou redução da quantidade do protozoário no sangue para níveis não habitualmente detectáveis pelo xenodiagnóstico. Isso poderia explicar o não infreqüente encontro de pacientes com xenodiagnóstico positivo entre numerosos outros negativos ou, então, o reaparecimento de positividade depois de longos períodos, de meses ou anos, de pesquisas xenodiagnósticas persistentemente negativas.

Relatamos um caso em que foi observado o reaparecimento de positividade xenodiagnóstica, 15 anos após reiterados exames negativos.

\section{Relato do caso}

Em janeiro de 1978, a paciente V.B., com 38 anos de idade e do sexo feminino, foi admitida em consulta no Ambulatório do Serviço de Doenças Transmissiveis, do Hospital do Servidor Público Estadual "Francisco Morato de Oliveira", de São Paulo, com sorologia positiva para doença de Chagas. Encontrou-se megarreto e, ao eletrocardiograma, constatou-se bloqueio completo de ramo direito. Foram realizados três xenodiagnósticos: o primeiro em fevereiro de 1978 e os dois subseqüentes em junho de 1978; todos

Serviço de Doenças Transmissíveis do Hospital do Servidor Público Estadual "Francisco Morato de Oliveira", de São Paulo.

Endereço para correspondência: Dr. Guido Carlos Levi. R. Pedro de Toledo 1800, 04039-000 São Paulo, SP, Brasil.

Recebido para publicação em 24/05/94. resultaram positivos. Em cada xenodiagnóstico aplicamos 60 ninfas de terceiro estádio do Triatoma infestans, divididas em quatro recipientes com 15.

Fez tratamento por meio do benzonidazol, na dose de $5 \mathrm{mg} / \mathrm{kg} / \mathrm{dia}$, totalizando $400 \mathrm{mg}$ nas 24 horas, em quatro tomadas de $100 \mathrm{mg}$. A administração perdurou por 60 dias, sem surgimento de efeitos colaterais. À evolução não notamos mudanças clínicas, eletrocardiográficas e radiológicas.

No primeiro ano após o tratamento os xenodiagnósticos, mensalmente, foram doze. Do segundo ao quinto ano, outros nove. Do sexto ao décimo-quarto ano foi feito um xenodiagnóstico, anualmente. No total, 31 xenodiagnósticos e todos negativos. Após quinze anos do tratamento, outro xenodiagnóstico mostrou resultado positivo. Neste período, a paciente não recebeu transfusão de sangue e nem teve oportunidade de se infectar em áreas endêmicas. Também, não apresentou quadro de imunossupressão, promovido por enfermidade ou por medicamento.

Os fatores que influem na evolução da infecção pelo Trypanosoma cruzi suscitam especulações, à espera de esclarecimentos finais. Assim sendo, não contamos com cabal compreensão acerca dos determinantes dos acometimentos orgânicos, como o cardíaco e o digestivo. Existem, porém, evidências favoráveis à patogênese imunológica eà participação do parasita na instalação das formas crônicas da doença de Chagas, nesse âmbito figurando o tratamento específico como provavelmente valioso para eliminar ou diminuir o parasitismo.

O benzonidazol é o fármaco presentemente mais empregado, pelo menos onde exercemos atividades, com a finalidade de coibir a infecção. Em uma série de 41 pacientes na fase crônica, medicados após xenodiagnóstico positivo e acompanhados por um período médio de seis anos e sete meses, obtivemos negativação do teste em 26 $(63,4 \%)$, administrando de 5 a $8 \mathrm{mg} / \mathrm{kg} / \mathrm{dia}$, durante um a dois meses.

$\mathrm{O}$ presente relato $\mathrm{diz}$ respeito a fato que 
Comunicação. Levi GC, Kallás EG, Mendonça JS, Amato Neto V. Reaparecimento da positividade de xenodiagnóstico 15 anos após tratamento específico da doença de Chagas. Revista da Sociedade Brasileira de Medicina Tropical 27:179-180, jul-set, 1994.

interpretamos como excepcional, atinente ao comportamento da parasitemia, estipulada por xenodiagnóstico, posteriormente a emprego do benzonidazol. O resultado dos 314 xenodiagnósticos negativos em 14 anos sugeriu efetividade por parte do composto antiparasitário. Não obstante, 15 anos depois, detectamos positividade.

O que observamos comprova que devemos ser extremamente cuidadosos ao recorrer à expressão cura parasitológica, quando vários xenodiagnósticos foram negativos posteriormente a tentativas de tratamentos específicos, pois pode ter ocorrido somente supressão temporária ou redução acentuada dos níveis parasitêmicos, dessa maneira impedindo que eles fiquem revelados pelas técnicas imperfeitas disponíveis.

\section{REFERÊNCIAS BIBLIOGRÁFICAS}

1. Köberle F, Oliveira JAM, Becker PFL. Patogenia da cardiopatia chagásica crônica. In: Davalos AR(ed) Enfermedad de Chagas, Los Amigos del Libro, La Paz p.183-214, 1978.

2. Pereira JB, Wilcox HPF, Coura JR. Evolução da cardiopatia chagásica crônica I-Influência da parasitemia. Revista da Sociedade Brasileira de Medicina Tropical 25:101-108, 1992. 